\title{
Risk factors for acute kidney injury following orthotopic liver transplantation: the impact of changes in renal function while patients await transplantation
}

\author{
Jose I Iglesias ${ }^{1,2^{*}}$, John A DePalma ${ }^{3}$, Jerrold S Levine ${ }^{4,5}$
}

\begin{abstract}
Background: Acute kidney injury (AKI) occurs commonly in the setting of orthotopic liver transplantation (OLT). To date, the correlation between AKI post-OLT and pre-operative changes in renal function has not been rigorously examined.

Methods: To determine the impact of pre-OLT changes in renal function on AKI post-OLT, as well as to identify risk factors for AKI, we analyzed the prospectively maintained NIDDK Liver Transplantation Database, which includes patients who received their first OLT between April 15, 1990, and June 30, 1994. We used the AKI Network definition of AKI.

Results: Surprisingly, univariate analysis revealed that worsening renal function while awaiting OLT was protective to the development of AKI post-OLT. Independent predictors of AKI were increased body mass index, increased Childs-Pugh-Turcott score, decreased urine output during cross-clamp, improved renal function while awaiting OLT, increased post-operative stroke volume, non-Caucasian race, and post-operative use of tacrolimus.

Conclusions: The correlation between improving renal function pre-OLT and AKI post-OLT may represent true protection (via ischemic pre-conditioning) or, alternatively, a masking of milder forms of AKI (via improved renal perfusion through correction of the cirrhotic milieu). These results highlight the complex interaction between liver and kidney disease, and suggest that not only the etiology but also the course of pre-OLT renal dysfunction may be a critical determinant of renal function post-OLT.
\end{abstract}

\section{Background}

Acute kidney injury (AKI) occurs commonly in the setting of orthotopic liver transplantation (OLT). The incidence varies widely, from $12 \%$ to $80 \%$, depending on the definition of AKI [1-4]. While awaiting OLT, patients often develop varying degrees of renal impairment, ranging from prerenal azotemia to hepatorenal syndrome and acute tubular necrosis. Although a majority of studies has identified a pre-operative elevation of serum creatinine ( $\mathrm{SCr}$ ) as a risk factor for the development of

\footnotetext{
*Correspondence: jiglesias@verizon.net

'Department of Medicine subsection of Nephrology, UMDNJ School of

Osteopathic Medicine, Stratford, NJ, 08084, USA

Full list of author information is available at the end of the article
}

AKI post-OLT, the timing and definition of AKI have been imprecise and inconsistent [1,4-6].

Transient changes of $\mathrm{SCr}$ in patients awaiting OLT most often occurs as a result of changes in renal perfusion. These changes, which are attributable to events and/or interventions such as large-volume paracentesis, diuretic therapy, sepsis, or gastrointestinal bleeding, tend to reduce the predictive power of pre-OLT SCr $[7,8]$. To date, the correlation between the development of AKI post-OLT and pre-operative changes in renal function, as assessed by $\mathrm{SCr}$, blood urea nitrogen (BUN), or estimated glomerular filtration rate (eGFR), has not been rigorously examined.

To determine the impact of pre-OLT changes in $\mathrm{SCr}$, BUN, and eGFR on development of AKI post-OLT, as 
well as to identify additional potential risk factors for AKI, we performed an analysis of the prospectively maintained National Institute of Diabetes and Digestive and Kidney Diseases (NIDDK) Liver Transplantation Database (LTD) [9]. Given the previous lack of consistency among studies in terms of criteria and timing of AKI, we used the Acute Kidney Injury Network (AKIN) definition of AKI [10].

\section{Methods}

\section{Study population}

The NIDDK-LTD was established to study the demographics, clinical and laboratory characteristics, and outcomes of patients evaluated for and undergoing OLT. The NIDDK-LTD contains extensive pre- and post-OLT data for 916 recipients from 3 clinical centers: Mayo Clinic, Rochester, Minnesota; University of Nebraska Medical Center, Omaha, Nebraska; and University of California, San Francisco, California. The NIDDK-LTD is maintained by the Epidemiology Data Coordinating Center at the University of Pittsburgh Graduate School of Public Health. Data collection for the NIDDK-LTD was conducted under protocols approved by the Committees on Human Research at all three participating clinical centers. Patient recruitment, which began on April 15, 1990, and ended on June 30, 1994, included all patients who received their first OLT during this interval. Prospective data on patients were collected using standardized data collection forms at initial evaluation, OLT, and regular intervals post-OLT. Information on the specific data collected from each patient has been published previously [9]. Although data were obtained during the 1990's, the range and depth of these prospectively obtained data still offer important clinical and pathophysiologic insight into the development and risk factors of AKI in patients with severe liver disease undergoing OLT.

The current study was designed as a retrospective cohort study. Of 916 patients enrolled in the NIDDKLTD, 688 patients were included in our analysis. We excluded 228 patients for the following reasons: age < 18 years $(n=138)$; organ transplantation in addition to OLT $(n=26)$; incomplete data $(n=5)$; and requirement for renal replacement therapy (RRT) at registration, during OLT, or on first day post-OLT $(n=59)$. Patients in the last category were excluded because the onset of AKI was felt to precede the peri-OLT period.

\section{Definitions}

In accord with AKIN recommendations, we defined AKI as a reduction of renal function (occurring within 48 hours), manifesting by either an absolute increase of $\mathrm{SCr} \geq 0.3 \mathrm{mg} / \mathrm{dL}$ or a percentage increase of $\mathrm{SCr} \geq$ $150 \%$. The last pre-OLT SCr was used as baseline. eGFR was determined using the 4-variable equation of the Modification of Diet in Renal Disease (MDRD) study group [11]. As urine output was only measured during the intra-operative period, we did not use urine output in defining AKI because of the unavailability of these data in the NIDDK-LTD database. Absolute changes of $\operatorname{SCr}(\triangle \mathrm{Scr}), \mathrm{BUN}(\triangle \mathrm{BUN})$, and eGFR $(\triangle \mathrm{eGFR})$ were calculated as pre-OLT minus registration values. Percent changes of $\mathrm{SCr}(\% \Delta \mathrm{SCr}), \mathrm{BUN}(\% \Delta \mathrm{BUN})$, and eGFR (\% $\triangle$ eGFR) were calculated by the following formula: $\%$ $\Delta=($ pre-OLT value/registration value $)-1 \times 100 \%$. Rates of change of $\mathrm{SCr}\left(\Delta \mathrm{SCr} / \Delta \mathrm{t}_{\text {wait }}\right)$, BUN $\left(\Delta \mathrm{BUN} / \Delta \mathrm{t}_{\text {wait }}\right)$, and eGFR $\left(\Delta \mathrm{eGFR} / \Delta \mathrm{t}_{\text {wait }}\right)$ were calculated by the following formula: rate of change $=$ absolute change $/$ wait list time.

\section{Data collection}

Pre-OLT data included routine demographic variables (age, sex, race), admission physiologic variables (complete blood count, electrolytes, clotting times, albumin, liver enzymes, total bilirubin, body surface area (BSA]), body mass index (BMI]), medications, comorbidities, MELD (Model for End-Stage Liver Disease) and ChildsPugh-Turcott scores, and renal variables (registration and pre-OLT values of BUN, SCr, and eGFR; $\triangle \mathrm{SCr}$, $\triangle \mathrm{BUN}$, and $\triangle \mathrm{eGFR} \% \Delta \mathrm{SCr}, \% \Delta \mathrm{BUN}$, and $\% \triangle \mathrm{eGFR}$; $\Delta \mathrm{SCr} / \Delta \mathrm{t}_{\text {wait }}, \Delta \mathrm{BUN} / \Delta \mathrm{t}_{\text {wait }}$, and $\Delta \mathrm{eGFR} / \Delta \mathrm{t}_{\text {wait }}$; and ${ }^{125} \mathrm{I}$ iodothalamate clearance at registration). BMI was calculated at the time of registration using actual body weight, including ascites, by the following formula: weight $(\mathrm{kg}) \div$ height (meters) ${ }^{2}$.

Peri- and intra-operative data included surgical and cross-clamp times; use of veno-veno bypass; administration of blood products (packed red blood cells [PRBC], platelets, fresh frozen plasma [FFP], cryoprecipitate, and colloid solutions); and hemodynamic variables (heart rate, mean arterial pressure [MAP], central venous pressure $[\mathrm{CVP}]$, mean pulmonary artery pressure [MPAP], pulmonary artery wedge pressure [PAWP], cardiac output $[\mathrm{CO}]$, stroke volume [SV], and systemic vascular resistance $[\mathrm{SVR}]$; and urine output. Hemodynamic variables and urine output were determined at the start of surgery, during cross-clamp (anhepatic phase) and following cross-clamp (reperfusion phase).

\section{Data analysis}

The primary outcome was development of AKI. As the number of patients with AKI stage 2 and stage 3 (AKI-2 and AKI-3) was too small for meaningful analysis (45 and 20 patients, respectively), all statistical analyses unless otherwise indicated were performed for patients who developed AKI (AKI) vs. those who did not (NO AKI).

Summary statistics were computed for both the AKI and NO AKI cohorts. Continuous variables were 
expressed as mean \pm standard deviation and compared by Student $\mathrm{t}$ test or Wilcoxon rank-sum test. Categorical variables were compared by Fisher's exact test or chisquare analysis. Comparison of cohorts included both univariate and multivariate analysis. Variables significant by univariate analysis at $\mathrm{p}<0.05$ were candidates for multivariate analysis. We performed logistic regression analysis with forward variable selection to determine variables independently predictive of AKI. Stepwise selections for logistic regression were based on the maximum likelihood ratio. For continuous variables, the odds ratio (OR) represents the relative amount by which the probability of obtaining the outcome variable increases or decreases if the independent variable is increased by exactly one unit. OR and their $95 \%$ confidence intervals $(\mathrm{CI})$ were determined by exponentiation of the regression coefficient or its upper and lower 95\% CI, respectively.

\section{Results}

\section{Univariate analyses of non-renal-function-associated risk} factors for AKI post-OLT

To determine factors correlating with AKI following OLT, we analyzed multiple routinely available demographic, clinical, and laboratory variables obtained during the pre-, intra- and post (first 48 hours)-operative periods for 916 OLT recipients registered in the NIDDK-LTD.

A total of 688 patients were evaluated, of whom 243 (35\%) developed AKI. Of these, 178 (73\%) developed AKI-1, 45 (18\%) AKI-2, and 20 (8\%) AKI-3. 6 patients (all with AKI-3) required RRT. We compared patients who developed AKI (AKI) with those who did not (NO AKI) by univariate analysis for multiple characteristics, including pre-operative factors (Table 1), associated comorbidities (Table 2), therapeutic interventions (Table 3 ), peri-operative urine outputs and operative variables (Table 4), and intra-operative hemodynamic variables (Table 5).

The following pre-operative variables were significantly associated with the development of AKI (Table $1)$ : male sex $(p=0.02)$, non-Caucasian race $(p=0.035)$, increased BSA $(\mathrm{p}<0.00001)$, increased BMI $(\mathrm{p}<$ $0.00001)$, decreased platelet count $(\mathrm{p}<0.00001)$, elevated prothrombin time $(\mathrm{p}<0.00001)$, elevated partial thromboplastin time $(\mathrm{p}=0.003)$, decreased serum albumin $(\mathrm{p}<0.00007)$, and decreased serum sodium $(\mathrm{p}=$ $0.0005)$.

The following diagnoses and co-morbidities were significantly associated with the development of AKI (Table 2): Childs Pugh Turcott score $(\mathrm{p}=0.00001)$, ascites while awaiting OLT $(\mathrm{p}=0.04)$ or at time of OLT $(\mathrm{p}=0.010)$, post-OLT mechanical ventilation $(\mathrm{p}<$ $0.00001)$, porto-systemic encephalopathy $(\mathrm{p}<0.00001)$,
Table 1 Univariate analysis of demographic and preoperative variables in patients with and without AKI

\begin{tabular}{llll}
\hline & No AKI $(\mathbf{n}=\mathbf{4 4 5})$ & AKI $(\mathbf{n}=\mathbf{2 4 3})$ & p value \\
\hline Age & $48.7 \pm 11.3$ & $50 \pm 10.2$ & 0.19 \\
Sex (male) & $232(52 \%)$ & $160(66 \%)$ & 0.02 \\
Race (Caucasian) & $369(82 \%)$ & $185(76 \%)$ & 0.035 \\
BSA $\left(\mathrm{m}^{2}\right)$ & $2.10 \pm 0.30$ & $2.26 \pm 0.22$ & 0.00001 \\
$\mathrm{BMI}\left(\mathrm{kg} / \mathrm{m}^{2}\right)$ & $25.3 \pm 4.4$ & $28 \pm 5.8$ & 0.00001 \\
$\mathrm{Hgb}(\mathrm{g} / \mathrm{dL})$ & $11.1 \pm 1.9$ & $11.0 \pm 1.9$ & 0.76 \\
WBC $\times 10^{9} / \mathrm{L}$ & $6.4 \pm 4.5$ & $6.1 \pm 3.4$ & 0.61 \\
Platelets $\times 10^{9} / \mathrm{L}$ & $137 \pm 135$ & $104 \pm 67$ & 0.00001 \\
PT (sec) & $14.9 \pm 4.7$ & $15.0 \pm 2.5$ & 0.00001 \\
PTT (sec) & $37.3 \pm 12.4$ & $40 \pm 13.7$ & 0.003 \\
Na (mmol/L) & $136 \pm 5.3$ & $135 \pm 5.9$ & 0.0005 \\
HCO $(\mathrm{mmol} / \mathrm{L})$ & $23.7 \pm 3.7$ & $24 \pm 4$ & 0.12 \\
AST (U/L) & $133 \pm 144$ & $130 \pm 125$ & 0.60 \\
ALT (U/L) & $94 \pm 144$ & $85 \pm 94$ & 0.40 \\
Total bilirubin (mg/dL) & $6.7 \pm 9$ & $7 \pm 10$ & 0.07 \\
Albumin (g/dL) & $3.1 \pm 0.6$ & $2.87 \pm 0.64$ & 0.00007 \\
\hline
\end{tabular}

alcoholic liver disease $(\mathrm{p}=0.048)$, chronic hepatitis $(\mathrm{p}=$ $0.04)$, and non-alcoholic steatohepatitis ( $<<0.0001)$.

Therapeutic interventions associated with the development of AKI included (Table 3): post-OLT use of loop diuretic $(\mathrm{p}=0.001)$ or tacrolimus $(\mathrm{p}<0.0001)$; intraoperative administration of PRBC $(\mathrm{p}=0.003)$, platelets $(\mathrm{p}=0.0002)$, or FFP $(\mathrm{p}<0.00002)$; lack of veno-venous bypass $(\mathrm{p}=0.044)$; and lack of cyclosporine $(\mathrm{p}=0.001)$.

Intra-operative urine output differed significantly for AKI patients only during cross-clamp, during which they had a decreased urine flow $(\mathrm{p}<0.00001)$ (Table 4). The duration of cross-clamp was shorter in AKI patients $(p=0.004)$. This may reflect a decreased use of venovenous bypass in AKI patients (Table 3), since crossclamp times were longer in AKI patients, when stratified according to use of venoveno bypass $(\mathrm{p}<0.0001$, not shown).

Hemodynamic variables were assessed at start of surgery, during cross-clamp, and after cross-clamp (Table 5). At start of surgery, AKI patients had increased $\mathrm{CO}$ $(\mathrm{p}<0.00001)$, increased SV $(\mathrm{p}<0.00001)$, and decreased SVR ( $\mathrm{p}<0.00002)$. During cross-clamp, AKI patients had higher heart rates $(\mathrm{p}=0.001)$ and higher MAP (0.043). Finally, following release of cross-clamp, AKI patients had increased CO $(\mathrm{p}<0.00001)$, increased SV $(\mathrm{p}<0.00003)$, and decreased SVR $(\mathrm{p}<0.00003)$.

\section{Univariate analyses of pre-OLT measures of renal function as risk factors for AKI post-OLT}

To determine the impact of renal function on development of AKI post-OLT, we evaluated multiple absolute measures of renal function obtained at registration or 
Table 2 Univariate analysis of co-morbidities, hepatic diagnoses, and complications in patients with and without AKI

\begin{tabular}{llll}
\hline & NO AKI (n = 445) & AKI (n = 243) & p value \\
\hline $\begin{array}{l}\text { Registration co-morbidities } \\
\text { Coronary artery disease }\end{array}$ & $15(3 \%)$ & $11(4 \%)$ & 0.52 \\
$\quad$ Diabetes & $64(14 \%)$ & $31(13 \%)$ & 0.64 \\
Hypertension & $69(16 \%)$ & $45(19 \%)$ & 0.33 \\
Hepatic disease leading to transplant & & & 0.048 \\
Alcoholic liver disease & $81(18 \%)$ & $60(25 \%)$ & 0.041 \\
Chronic hepatitis & $162(36 \%)$ & $108(44 \%)$ & 0.74 \\
Hepatitis B & $28(6 \%)$ & $17(7 \%)$ & 0.31 \\
Hepatitis C & $63(15 \%)$ & $42(18 \%)$ & 0.00001 \\
Non-alcoholic steatohepatitis & $160(36 \%)$ & $52(21 \%)$ & 0.04 \\
Complications while on waiting list & & & 0.01 \\
Ascites (registration) & $325(73 \%)$ & $195(82 \%)$ & 0.40 \\
Ascites (pre-operative) & $289(65 \%)$ & $181(74 \%)$ & 0.26 \\
Variceal bleed (any time) & $142(32 \%)$ & $70(29 \%)$ & 0.09 \\
Porto-systemic shunt (any time) & $33(7 \%)$ & $24(10 \%)$ & 0.00001 \\
Bacterial peritonitis (any time) & $59(13 \%)$ & $44(17 \%)$ & 0.8 \\
Porto-systemic encephalopathy (any time) & $195(44 \%)$ & $141(58 \%)$ & 0.00001 \\
MELD score & $15.7 \pm 6$ & $15.8 \pm 5$ & $9.1 \pm 1.5$ \\
Child-Pugh-Turcott score & $8.4 \pm 1.6$ & $171(70 \%)$ & 0.00001 \\
Other & $271(61 \%)$ & $24(10 \%)$ & \\
Mechanical ventilation (post-operative) & $26(6 \%)$ & \\
Retransplant & & \\
\hline
\end{tabular}

pre-OLT, as well as changes in these same measures of renal function while awaiting OLT (Table 6). No correlation existed between AKI post-OLT and absolute values of $\mathrm{SCr}, \mathrm{BUN}$, and eGFR, either at registration or pre-OLT.

Unexpectedly, univariate analysis revealed an inverse relationship between improving renal function while awaiting OLT and development of AKI post-OLT. On average, AKI patients had a greater degree of renal functional preservation, or even improvement, while awaiting OLT than did NO AKI patients. Thus, AKI post-OLT was significantly correlated with a decreased $\Delta \mathrm{SCr}$, a decreased $\% \Delta \mathrm{SCr}$, and a decreased $\Delta \mathrm{SCr} / \Delta \mathrm{t}_{\text {wait }}(\Delta \mathrm{SCr}=$ $0.036 \pm 0.390$ vs. $0.13 \pm 0.70 \mathrm{mg} / \mathrm{dL}, \mathrm{p}=0.017 ; \% \Delta \mathrm{SCr}$ $=9 \pm 40 \%$ vs. $19 \pm 67 \%, \mathrm{p}=0.014$; and $\Delta \mathrm{SCr} / \Delta \mathrm{t}_{\text {wait }}=$ $-0.0014 \pm 0.015$ vs. $0.004 \pm 0.034 \mathrm{mg} / \mathrm{dL} / \mathrm{day}, \mathrm{p}=$ 0.007). Similarly, the development of AKI was significantly correlated with a decreased $\triangle \mathrm{eGFR}$, a decreased $\% \Delta \mathrm{eGFR}$, and a decreased $\Delta \mathrm{eGFR} / \Delta \mathrm{t}_{\text {wait }}(\Delta \mathrm{eGFR}=-2.6$ \pm 31 vs. $-7.4 \pm 26 \mathrm{ml} / \mathrm{min}, \mathrm{p}=0.021 ; \% \Delta \mathrm{eGFR}=-3.7 \pm$ $45 \%$ vs. $3.3 \pm 38 \%, \mathrm{p}=0.014$; and $\Delta \mathrm{eGFR} / \Delta \mathrm{t}_{\mathrm{wait}}=$ $-0.0014 \pm 0.015$ vs. $0.004 \pm 0.034 \mathrm{ml} / \mathrm{min} / \mathrm{day}, \mathrm{p}=$ 0.007).

\section{Multivariate analysis of risk factors for AKI post-OLT}

We used forward stepwise logistic regression analysis to determine which variables identified by univariate analyses (Tables 1, 2, 3, 4, 5, 6) were independent predictors of AKI post-OLT (Table 7). Independent predictors of AKI, in descending order of coefficient of determination, were increased BMI, increased ChildsPugh-Turcott score, decreased urine output during cross-clamp, improved renal function while awaiting OLT, increased post-OLT SV, non-Caucasian race, and post-OLT use of tacrolimus.

\section{Categorical analysis of effect of changes in renal function} while awaiting OLT on post-operative AKI

The emergence of improved renal function as an independent risk factor for AKI post-OLT was unanticipated. To confirm the impact of pre-operative changes of renal function on AKI post-OLT, we performed several additional analyses. In the first, we subdivided patients into those whose renal function remained the same or declined while awaiting OLT vs. those whose renal function improved (Table 8 ). AKI occurred in $42 \%$ of patients whose eGFR improved vs. $32 \%$ of those whose eGFR remained the same or decreased ( $\mathrm{p}=$ $0.014, \mathrm{OR}=1.53,95 \% \mathrm{CI}=1.10-2.20)$. A similar trend was observed in comparing patients whose $\mathrm{SCr}$ increased vs. those whose $\mathrm{SCr}$ remained the same or decreased, although the difference did not achieve statistical significance $(38 \%$ vs. $32 \%, p=0.11, \mathrm{OR}=1.30,95 \%$ $\mathrm{CI}=0.95-1.80)$.

In the second analysis, we subdivided patients according to $\Delta \mathrm{SCr} / \Delta \mathrm{t}_{\mathrm{wait}}$ (Figure 1). Negative values of $\Delta \mathrm{SCr} /$ 
Table 3 Univariate analysis of effect of therapeutic interventions in patients with and without AKI

\begin{tabular}{|c|c|c|c|}
\hline & $\begin{array}{l}\text { NO AKI } \\
(n=445)\end{array}$ & $\begin{array}{l}\text { AKI } \\
(n=243)\end{array}$ & $p$ value \\
\hline \multicolumn{4}{|l|}{ Wait list (any time) } \\
\hline Aminoglycoside & $55(12 \%)$ & $24(10 \%)$ & 0.33 \\
\hline Inotrope use & $367(82 \%)$ & $198(81 \%)$ & 0.75 \\
\hline Time of surgery & 407(91\%) & $213(87 \%)$ & 0.10 \\
\hline Anhepatic phase (Cross clamp) & $421(95 \%)$ & $228(94 \%)$ & 0.73 \\
\hline Post operative & 414(93\%) & $224(92 \%)$ & 0.75 \\
\hline \multicolumn{4}{|l|}{ Pre-operative } \\
\hline Loop diuretic & $172(38 \%)$ & $108(44 \%)$ & 0.14 \\
\hline Spironolactone & $226(51 \%)$ & $133(53 \%)$ & 0.30 \\
\hline \multicolumn{4}{|l|}{ Intra-operative } \\
\hline Albumin (ml) & $1059 \pm 1311$ & $1199 \pm 1509$ & 0.50 \\
\hline Colloid (ml) & $2413 \pm 2400$ & $2428 \pm 3336$ & 0.30 \\
\hline Packed red blood cells (ml) & $3440 \pm 3281$ & $3974 \pm 3758$ & 0.003 \\
\hline Platelets (ml) & $813 \pm 98$ & $1082 \pm 1118$ & 0.0002 \\
\hline Cryoprecipitate (ml) & $228 \pm 490$ & $212 \pm 405$ & 0.90 \\
\hline Fresh frozen plasma (ml) & $3695 \pm 2759$ & $4582 \pm 3121$ & 0.00002 \\
\hline Venovenous bypass & $270(61 \%)$ & $128(53 \%)$ & 0.044 \\
\hline \multicolumn{4}{|l|}{ Post-operative } \\
\hline Loop diuretic use & $334(75 \%)$ & $208(85 \%)$ & 0.001 \\
\hline Cyclosporin use & $330(74 \%)$ & $150(61 \%)$ & 0.001 \\
\hline Tacrolimus use & $46(10 \%)$ & $42(17 \%)$ & 0.012 \\
\hline Cyclosporin level, day 1 & $298 \pm 220$ & $269 \pm 233$ & 0.09 \\
\hline Cyclosporin level, day 3 & $816 \pm 517$ & $793 \pm 548$ & 0.75 \\
\hline Tacrolimus level, day 1 & $7.8 \pm 11.0$ & $6.2 \pm 5.3$ & 0.58 \\
\hline Tacrolimus level, day 3 & $9.2 \pm 13.0$ & $15.6 \pm 18.0$ & 0.14 \\
\hline
\end{tabular}

$\Delta \mathrm{t}_{\text {wait }}$ indicate improved renal function while awaiting OLT, whereas positive values indicate worsened renal function. In general, for those deciles of $\Delta \mathrm{SCr} / \Delta \mathrm{t}_{\text {wait }}$ corresponding to improved renal function $\left(\Delta \mathrm{SCr} / \Delta \mathrm{t}_{\text {wait }}\right.$ $<0$ ), an increased percentage of patients developed AKI. The opposite trend was observed for those deciles

Table 4 Univariate analysis of urine output and other operative variables in patients with and without AKI

\begin{tabular}{llll}
\hline & $\begin{array}{l}\text { NO AKI } \\
(\mathbf{n = 4 4 5})\end{array}$ & $\begin{array}{l}\text { AKI } \\
(\mathbf{n = 2 4 3 )}\end{array}$ & $\begin{array}{l}\mathbf{p} \\
\text { value }\end{array}$ \\
\hline $\begin{array}{l}\text { Operative variables } \\
\quad \text { Days on waiting list }\end{array}$ & $149 \pm 152$ & $173 \pm 206$ & 0.36 \\
$\begin{array}{l}\text { Duration of surgery (hrs: } \\
\text { mins) }\end{array}$ & $6: 44 \pm 1: 47$ & $6: 46 \pm 1.58$ & 0.80 \\
$\quad \begin{array}{lll}\text { Duration of cross-clamp } \\
\text { (hrs: mins) }\end{array}$ & $1: 19 \pm 0: 35$ & $1: 11 \pm 0: 33$ & 0.004 \\
$\begin{array}{l}\text { Urine output (ml) } \\
\quad \text { Surgery start }\end{array}$ & & & \\
$\quad \begin{array}{l}\text { Cross-clamp } \\
\quad \text { Post-operative }\end{array}$ & $760 \pm 672$ & $810 \pm 903$ & 0.40 \\
\hline
\end{tabular}

Table 5 Univariate analysis of intra-operative hemodynamic factors in patients with and without AKI

\begin{tabular}{llll}
\hline & $\begin{array}{l}\text { NO AKI } \\
(\mathbf{n}=\mathbf{4 4 5})\end{array}$ & $\begin{array}{l}\text { AKI } \\
(\mathbf{n}=\mathbf{2 4 3})\end{array}$ & p value \\
\hline Surgery start & & & \\
Heart rate (beats per minute) & $85 \pm 15$ & $86 \pm 17$ & 0.75 \\
MAP (mm Hg) & $75 \pm 13$ & $77 \pm 13$ & 0.14 \\
CVP (mm Hg) & $12.6 \pm 5.4$ & $12.7 \pm 5.2$ & 0.76 \\
MPAP (mm Hg) & $19 \pm 5.8$ & $20.6 \pm 8.0$ & 0.17 \\
PAWP (mm Hg) & $15.3 \pm 4.9$ & $16.0 \pm 5.3$ & 0.34 \\
CO (L/min) & $8.5 \pm 3.3$ & $9.7 \pm 3.7$ & 0.00001 \\
SV (ml) & $101 \pm 37$ & $117 \pm 72$ & 0.00001 \\
SVR (dynes) & $667 \pm 279$ & $599 \pm 240$ & 0.00002
\end{tabular}

\section{Cross-clamp}

Heart rate (beats per minute) $\quad 99.0+17.0 \quad 103.0+16.0=0.001$

MAP

$82.0 \pm 12.5 \quad 84.0 \pm 13.0 \quad 0.043$

CVP

$10.1 \pm 5.4$

$84.0 \pm 13.0-0.043$

MPAP

$14.3 \pm 6.3$

$14.7 \pm 7.2 \quad 0.87$

PAWP

$\begin{array}{lll}11.8 \pm 4.7 & 11.5 \pm 4.4 & 0.74\end{array}$

CO

$\begin{array}{lll}6.9 \pm 2.4 & 7.8 \pm 7.5 & 0.23\end{array}$

SV

$71.0 \pm 26.9 \quad 77.8 \pm 64.0 \quad 0.97$

SVR

$950.0 \pm 415.0 \quad 970.0 \pm 491.0 \quad 0.86$

\section{Post-cross-clamp}

Heart rate (beats per minute) $\quad 98.0 \pm 14.0 \quad 98.0 \pm 15.0 \quad 0.50$ MAP

CVP

$74.0 \pm 10.6$

$75.0 \pm 10.4 \quad 0.50$

MPAP

$12.1 \pm 4.6$

$12.3 \pm 4.9 \quad 0.60$

PAWP

CO

$20.0 \pm 5.3$

$21.0 \pm 7.1$

0.16

$14.7 \pm 4.8$

$15.3 \pm 4.5$

0.32

$11.0 \pm 3.7$

$12.6 \pm 3.7$

0.00001

SV

$114.0 \pm 38.0$

$134 \pm 77$

0.00003

SVR

$482.0 \pm 167.0$

$432.0 \pm 161.0$

0.00003

Abbreviations: $\mathrm{CO}$, cardiac output; CVP, central venous pressure; MAP, mean arterial pressure; MPAP, mean pulmonary artery pressure; PAWP, pulmonary artery wedge pressure; SV, stroke volume; SVR, systemic vascular resistance.

corresponding to stable or worsening renal function $\left(\Delta \mathrm{SCr} / \Delta \mathrm{t}_{\text {wait }} \geq 0\right)$. The inverse relationship between degree of renal functional improvement and risk for AKI was statistically significant $(\mathrm{p}=0.008)$.

Finally, we repeated our analysis including the 11 patients who required RRT on the first day post-OLT. These patients were excluded because the onset of their AKI was felt to precede the peri-OLT period and therefore to be independent of operative factors. It is possible, however, that their exclusion may have led to an underrepresentation of patients with declining renal function while awaiting OLT. Notably, even upon inclusion of these patients, a significant correlation still existed between the development of AKI and the same pre-OLT renal functional variables: namely, decreased $\triangle \mathrm{SCr}$ and \% $\triangle \mathrm{SCr}$; decreased $\triangle \mathrm{eGFR}$ and $\% \triangle \mathrm{eGFR}$; decreased $\triangle \mathrm{SCr} /$ $\Delta \mathrm{t}$ and $\Delta \mathrm{eGFR} / \Delta \mathrm{t}$ (Additional file 1 , Table S1). 
Table 6 Univariate analysis of measures of renal function in patients with and without AKI

\begin{tabular}{|c|c|c|c|}
\hline Renal functional parameter & NO AKI $(n=445)$ & AKI $(n=243)$ & $p$ value \\
\hline lodothalamate clearance $(\mathrm{ml} / \mathrm{min})$ (registration) & $97 \pm 35$ & $105 \pm 66$ & 0.44 \\
\hline $\mathrm{SCr}(\mathrm{mg} / \mathrm{dL})$ (registration) & $1.05 \pm 0.60$ & $1.05 \pm 0.40$ & 0.46 \\
\hline BUN (mg/dL) (registration) & $19 \pm 18$ & $17 \pm 14$ & 0.16 \\
\hline eGFR (ml/min) (registration) & $83 \pm 31$ & $84 \pm 32$ & 0.81 \\
\hline $\mathrm{SCr}$ (mg/dL) (pre-operative) & $1.19 \pm 0.60$ & $1.09 \pm 0.40$ & 0.45 \\
\hline BUN (mg/dL) (pre-operative) & $19.7 \pm 17.0$ & $20.0 \pm 15.4$ & 0.66 \\
\hline eGFR (ml/ml) (pre-operative) & $76.0 \pm 31.0$ & $81.4 \pm 33.0$ & 0.058 \\
\hline$\Delta \mathrm{SCr}(\mathrm{mg} / \mathrm{dL})$ & $0.13 \pm 0.70$ & $0.036 \pm 0.390$ & 0.017 \\
\hline$\triangle B \cup N(\mathrm{mg} / \mathrm{dL})$ & $1.08 \pm 23.0$ & $3.05 \pm 21.0$ & 0.11 \\
\hline$\triangle \mathrm{eGFR}(\mathrm{ml} / \mathrm{min})$ & $-7.4 \pm 26.0$ & $-2.6 \pm 31.0$ & 0.021 \\
\hline$\% \Delta \mathrm{SCr}$ & $19 \pm 67$ & $9 \pm 40$ & 0.014 \\
\hline$\% \triangle B \cup N$ & $58 \pm 170$ & $72 \pm 181$ & 0.74 \\
\hline$\% \triangle \mathrm{eGFR}$ & $-3.7 \pm 45.0$ & $3.3 \pm 38.0$ & 0.014 \\
\hline$\Delta \mathrm{SCr} / \Delta \mathrm{t}(\mathrm{mg} / \mathrm{dL} /$ day) $(\mathrm{mg} / \mathrm{dL} /$ day $)$ & $0.004 \pm 0.034$ & $-0.0014 \pm 0.015$ & 0.007 \\
\hline$\Delta \mathrm{BUN} / \Delta \mathrm{t}(\mathrm{mg} / \mathrm{dL} / \mathrm{day})$ & $0.12 \pm 1.30$ & $0.166 \pm 0.90$ & 0.114 \\
\hline$\Delta \mathrm{eGFR} / \Delta \mathrm{t}(\mathrm{ml} / \mathrm{min} /$ day $)$ & $-0.15 \pm 1.29$ & $0.04 \pm 0.66$ & 0.006 \\
\hline
\end{tabular}

Abbreviations: BUN, blood urea nitrogen; eGFR, estimated glomerular filtration rate; $\mathrm{SCr}$, serum creatinine.

To convert to S.I. units: multiply BUN by 0.357 ( $\mathrm{mmol} / \mathrm{L}$ ); multiply $\mathrm{SCr}$ by $88.4(\mu \mathrm{mol} / \mathrm{L})$.

Follow up at 7 days of AKI and NO AKI patients

We examined the outcome of AKI and NO AKI patients at 7 days post-OLT. Of the 243 patients who developed AKI within 2 days of OLT, 3 died, 160 recovered, and 80 still suffered from AKI (53 AKI-1, 3 AKI-2, and 24 AKI$3)$. Eight patients received RRT. Of the 445 patients without AKI in the first 2 days post-OLT, 4 died and 291 subsequently developed AKI (77 AKI-1, 13 AKI-2, 60 AKI$3)$, with 25 requiring RRT. The etiology and risk factors for AKI developing $>2$ days post-OLT are likely distinct from those for AKI in the immediate period post-OLT.

\section{Discussion}

We performed a retrospective analysis of patients enrolled in the NIDDK-LTD to identify risk factors for the development of AKI immediately following OLT ( $\leq 48$ hours). We examined a variety of demographic, clinical, and laboratory variables obtained at registration, pre-OLT, intra-operatively, and after OLT in 688 patients undergoing OLT between April, 1990, and June, 1994. Our most important finding is that those patients whose renal function declined while awaiting OLT, as assessed by an increased $\mathrm{SCr}$ or a decreased eGFR, were at decreased risk for AKI post-OLT. This seemingly paradoxical result is in contrast to previous studies, in which pre-OLT renal dysfunction was identified as a strong predictor of AKI post-OLT. In our analysis, the absolute level of renal function, as assessed by ${ }^{125}$ I-iodothalamate clearance, eGFR, SCr, or BUN, obtained at registration or immediately pre-OLT, did not differ between patients with and without AKI. Rather, the change in renal function in the interval from registration to OLT was the critical determinant whether OLT recipients developed AKI.

Several considerations bear on the discrepancy between our results and those of previous studies. The most important is a previous lack of consensus with respect to the definition and timing of AKI. Earlier studies varied widely in the definition and timeframe in which AKI was studied $[12,13]$. To circumvent these issues, we used the AKIN definition of AKI, and limited our analysis to within 48 hours following OLT.

Table 7 Multivariate logistic regression analysis of risk factors for the development of all AKI

\begin{tabular}{|c|c|c|c|c|c|c|}
\hline Variable & Regression coefficient & SE & $p$ value & OR & $95 \% \mathrm{Cl}$ & Coefficient of determination* \\
\hline Body mass index & 0.085 & 0.02 & 0.00001 & 1.09 & $1.045-1.130$ & 0.070 \\
\hline Childs-Pugh-Turcot score & 0.27 & 0.07 & 0.00001 & 1.31 & $1.15-1.49$ & 0.051 \\
\hline Urine output (cross-clamp) & -0.002 & 0.001 & 0.003 & 0.99 & $0.996-0.990$ & 0.032 \\
\hline$\Delta \mathrm{SCr} / \Delta \mathrm{t}(\mathrm{mg} / \mathrm{dL} /$ day $)$ & -0.002 & 0.001 & 0.019 & 0.99 & $0.97-1.00$ & 0.030 \\
\hline Stroke volume (post-operative) & 0.006 & 0.003 & 0.027 & 1.006 & $1.001-1.011$ & 0.015 \\
\hline Race (non-Caucasian) & 0.662 & 0.25 & 0.008 & 1.93 & $1.18-3.10$ & 0.013 \\
\hline Tacrolimus (post-operative) & 0.662 & 0.29 & 0.022 & 1.93 & $1.1-3.4$ & 0.011 \\
\hline
\end{tabular}

* The cumulative coefficient of determination for all variables combined is 0.222 . 
Table 8 Categorical analysis of measures of renal function in patients with and without AKI

\begin{tabular}{|c|c|c|c|c|c|}
\hline & NO AKI $(n=445)$ & $A K I(n=243)$ & $\mathrm{p}$ value & OR & $95 \% \mathrm{Cl}$ \\
\hline Increased eGFR & $130(29 \%)$ & 94 (39\%) & 0.014 & 1.53 & $1.10-2.20$ \\
\hline Decreased (or unchanged) eGFR & $315(71 \%)$ & 149 (61\%) & & & \\
\hline Decreased (or unchanged) $\mathrm{SCr}$ & $227(51 \%)$ & $140(57 \%)$ & 0.11 & 1.30 & $0.95-1.80$ \\
\hline Increased SCr & $218(49 \%)$ & $103(43 \%)$ & & & \\
\hline
\end{tabular}

The issue of timing is subtle but potentially critical. While AKI can occur anytime following OLT, its etiology likely varies with time from surgery. AKI occurring immediately following OLT and AKI occurring later during the post-OLT course are probably distinct entities with distinct predisposing factors and epidemiology. Moreover, as compared to the general surgical population, patients undergoing OLT have both shared and specific risk factors for AKI [13]. Our interest was in risk factors specific to OLT. We reasoned that the shorter the interval between OLT and AKI, the more likely that AKI would reflect factors particular to OLT.

In addition to issues of timing, most previous studies, identifying pre-operative renal dysfunction as a risk factor for AKI, have focused on more severe degrees of renal dysfunction. For example, renal dysfunction pre-OLT has been defined categorically as a $\mathrm{SCr}>1.5 \mathrm{mg} / \mathrm{dL}$, while
AKI post-OLT has been defined as a requirement for RRT or a doubling of SCr [14-17]. Contreras et al showed that an elevated pre-OLT SCr was the strongest predictor of AKI requiring RRT within the first 7 days post-OLT [12]. Similarly, Sanchez et al found that a SCr $>1.9 \mathrm{mg} / \mathrm{dL}$ or a BUN $>27 \mathrm{mg} / \mathrm{dL}$ were strong predictors of AKI requiring RRT, although these authors did not indicate clearly the timeframe post-OLT that they studied [13].

In contrast, we used continuous measures of renal function pre-OLT as well as a standardized definition for post-OLT AKI. To our knowledge, no studies have evaluated post-OLT AKI by AKIN definitions, and only two studies have used the RIFLE criteria, on which the AKIN definitions are based [18]. Like AKIN, RIFLE uses three categories of graded renal dysfunction (denoted risk, injury, and failure). Earlier studies using RIFLE criteria offer some support to our conclusions. O'Reardon

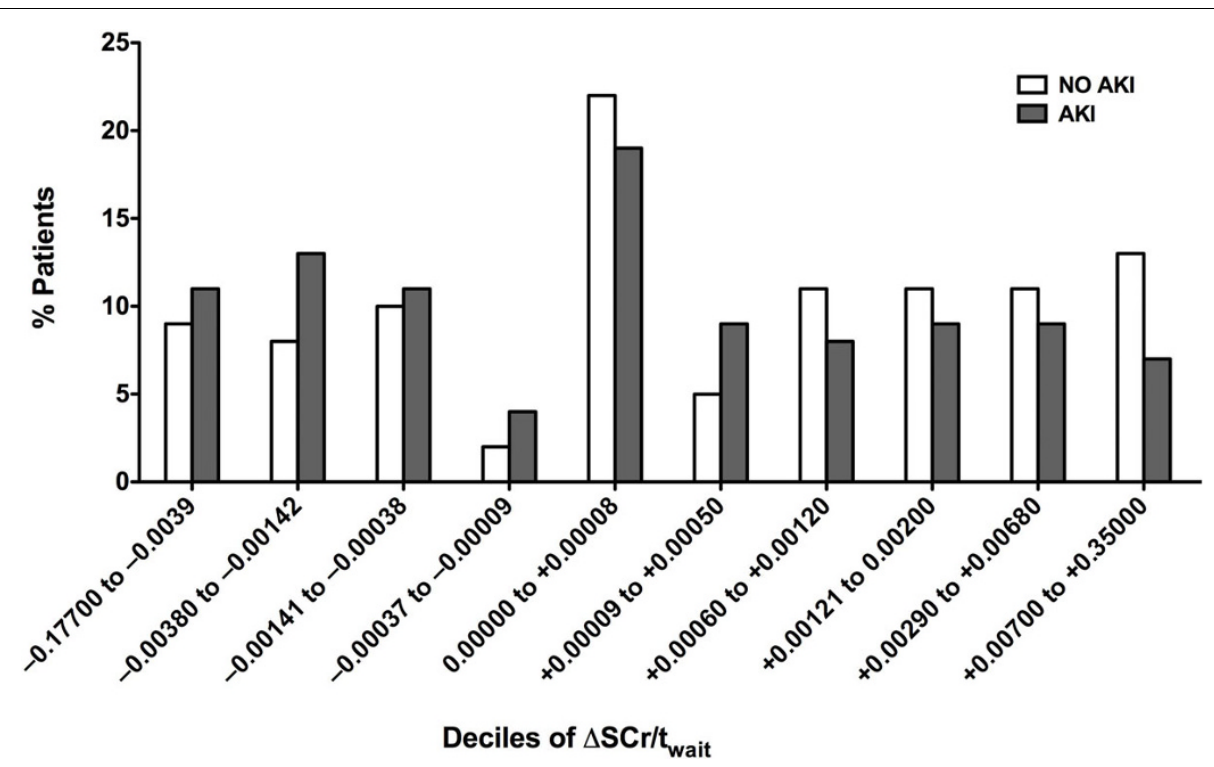

Figure 1 Distribution of rates of change of serum creatinine ( $\Delta \mathrm{SCr} / \Delta$ twait) while awaiting orthotopic liver transplantation (OLT) in patients who did or did not develop post-OLT acute kidney injury (AKI). Patients were stratified in order to according to $\Delta \mathrm{S} C \mathrm{r} / \Delta \mathrm{twait}$ and subdivided into deciles containing equal numbers of patients. $\Delta \mathrm{SCr} / \Delta \mathrm{tw}$ ait was defined as the absolute change of serum $\mathrm{creatine}(\Delta \mathrm{SCr})$ while awaiting OLT (SCr pre-OLT minus SCr at registration) divided by the time awaiting OLT. The percentage of the total number of patients $(n=$ 243) who developed AKI (AKI) falling within each decile is plotted. Similarly, the percentage of the total number of patients $(n=445)$ who did not develop AKI (NO AKI) within each decile is plotted. Negative values of $\Delta \mathrm{SCr} / \Delta t$ twait correspond to improved renal function, while positive values of $\Delta \mathrm{SCr} / \Delta \mathrm{twait}$ correspond to worsened renal function. The inverse relationship between degree of renal functional improvement and risk for AKI was statistically significant $(p=0.008)$. 
et al found that an increased $\mathrm{SCr}$ pre-OLT was a risk factor for the development of renal failure, the most severe RIFLE category [4]. Notably, an elevation of $\mathrm{SCr}$ pre-OLT was not a risk factor for renal injury, a less severe RIFLE category. As in our study, patients who developed renal injury had better pre-operative renal function, with lower SCr and higher eGFR. It should be noted, however, that these authors evaluated renal failure and injury at a later time, namely, two weeks postOLT [4]. While Guitard et al, in a retrospective analysis of 100 OLT patients, also using RIFLE criteria, found that an elevated $\mathrm{SCr}$ pre-OLT was associated with renal failure by univariate analysis, elevated pre-OLT $\mathrm{SCr}$ dropped out as an independent predictor by multivariate analysis [18].

Several potential explanations may account for the apparent protective effect of pre-OLT renal functional impairment on the development of AKI post-OLT. First, AKI in these patients may have been masked by an improvement in renal perfusion, leading to increased eGFR and decreased SCr. Because OLT reverses many circulatory abnormalities associated with decreased renal perfusion [19], patients often recover renal function post-OLT. It is estimated that a majority of patients awaiting OLT have some form of reversible renal dysfunction due to diminished renal perfusion [20-23]. Thus, in our study, it is possible that pre-OLT declines in renal function were reflective of changes in renal perfusion rather than intrinsic injury or loss of renal mass. OLT, by improving renal perfusion and inducing a decline in $\mathrm{SCr}$ and rise in eGFR, could mask small deteriorations in renal function consistent with milder stages of AKI. In accord with this possibility is the fact that an improvement of renal function was a more powerful predictor for AKI-2/3 than for AKI-1 (Additional file 1 Tables S2, S3, and S4). Second, consideration should be given to the possibility that the pre-OLT decline in $\mathrm{SCr}$ among patients developing AKI is dilutional rather than indicative of improved renal function. While we cannot formally exclude this possibility, it is noteworthy that AKI patients sustained a loss, rather than gain, of weight $(14.5 \pm 32.0 \mathrm{~kg})$ during the time from registration until OLT, making it unlikely that their decline of $\mathrm{SCr}$ can be attributed to dilutional effects. Third, the pre-OLT decline in SCr may reflect a loss of lean body mass, and it is the debilitation resulting from such a loss of lean body mass that predisposes to the development of AKI. Finally, pre-operative declines of renal dysfunction may truly protect patients from AKI, perhaps via ischemic preconditioning, as previously described for liver, kidney, and heart [24-26].

Other independent predictors of AKI post-OLT were increased BMI, decreased urine output during crossclamp, increased post-OLT SV, non-Caucasian race,
post-OLT use of tacrolimus, and Childs Pugh Turcott score. These factors likely reflect the severity of underlying liver disease (Childs-Pugh-Turcott score and increased post-OLT SV) and/or degree of renal ischemia (decreased urine output and post-OLT tacrolimus). Non-Caucasian race has been identified in other studies as a risk factor for AKI, for example, among patients undergoing cardiopulmonary bypass $[27,28]$. Other studies have noted an association between tacrolimus and renal dysfunction [29-32].

An increased BMI was the strongest independent predictor of AKI post-OLT. A larger BMI may affect dosing and volume of distribution for drugs with a potential for nephrotoxicity [33]. Obese patients may have a greater post-operative inflammatory response with increased risk of multi-organ dysfunction [34]. In addition, patients with larger BMI may receive small-for-size hepatic grafts with resultant graft dysfunction and renal hypoperfusion [35]. Finally, the possibility exists that a larger BMI reflects volume overload and profound ascites, with the observed decline of $\mathrm{SCr}$ in AKI patients being a dilutional effect rather than an indication of improved renal function. As discussed above, this seems inlikely, since these patients lost, rather than gained, considerable weight while awaiting OLT. However, it is important to note that the determination of BMI in patients with ascites is fraught with error, and no formula for BMI in these patients has been validated.

Our study has several strengths. The most important is our use of the NIDDK-LTD, which contains prospective data from three centers over a five-year period. Also, we evaluated risk factors for AKI over a prolonged timeframe, from registration up to and following OLT. Finally, we used a very rigorous definition of AKI, as well as continuous measures of renal function, and we limited our analysis to the initial 48 hours post-OLT.

Although data on urine output were not available for the pre- and post-OLT periods, AKI and NO AKI patients did not differ in relative weight change from immediately before OLT to either post-OLT day 1 (1.2 $\pm 37.0 \mathrm{~kg}$ vs. $1.2 \pm 33.0 \mathrm{~kg}, \mathrm{p}=0.995)$ or post OLT day $3(-0.2 \pm 37.0 \mathrm{~kg}$ vs. $-1.4 \pm 35.0 \mathrm{~kg}, \mathrm{p}=0.70)$. These data lend support to the notion that the observed differences in renal outcome post-OLT in AKI vs. NO AKI patients cannot be attributed to differences in perioperative volume status or extent of fluid administration. Moreover, as discussed above, AKI patients on average sustained a weight loss of $\sim 14 \mathrm{~kg}$ while awaiting OLT. Indeed, it is noteworthy that $\mathrm{SCr}$ decreased despite a large decrease of weight, of which much was likely achieved through fluid removal. Taken together, the observed pre-OLT decrease of SCr among AKI patients would seem to be independent of dilutional factors. 
We note the following limitations to our study. First, we were unable to determine the etiology of renal dysfunction in our patients. The distinction between prerenal and renal causes of renal dysfunction pre-OLT may impact on the interpretation and significance of improved renal function as a risk factor for AKI post-OLT.

Third, we used the MDRD formula to determine eGFR. Estimates of renal function in cirrhotic patients that are based on $\mathrm{SCr}$ are known to overestimate the true GFR. However, it is important to emphasize that our analysis was limited to the correlation between changes (not absolute levels) of eGFR and the development of AKI following OLT.

Finally, although we included MELD scores in our analysis, our patients came from the pre-MELD era, and risk factors for AKI may differ in the current era, in which patients undergo OLT with more severe renal function. In the last two decades, there have been medical and surgical advances in the management of patients undergoing OLT. These include caval sparing, split liver transplants, diminished usage of veno-veno bypass, shorter anhepatic times, improved anesthetic techniques, and strategies to minimize calcineurin exposure [36-38]. These improvements, while decreasing the risk for AKI during OLT, are counterbalanced by two factors, which simultaneously increase the risk for AKI: transplantation of patients with higher MELD scores, and expansion of the donor pool to include non-heart-beating and "expanded-criteria donors [39-41]." With those caveats in mind, we believe that the impact of pre-operative changes in renal function on the risk for peri-operative OLT AKI is a reflection of the cirrhotic hemodynamic milieu per se, rather than any specific level of hepatic dysfunction, as indicated by the MELD score. In addition, our results may have a more general relevance and extend to surgical procedures other than OLT in patients with end stageliver disease. Analysis of newer databases should help to resolve both of these points.

\section{Conclusion}

In summary, our study is the largest to date on the development of AKI post-OLT using AKIN definitions. Our most important finding is that the absolute level of renal function pre-OLT was not a risk factor for AKI post-OLT. Rather, patients whose renal function declined while awaiting OLT were protected from AKI. This finding may represent true protection, via perhaps ischemic pre-conditioning, or represent a masking of milder forms of AKI, via correction of the cirrhotic milieu and improved renal perfusion. Irrespective of mechanism, the seemingly paradoxical result that declining renal function identifies patients at lesser risk for AKI post-OLT underscores the complex interrelationship between liver and kidney disease. Given the scarcity of organs available for simultaneous liver-kidney transplant, there is a need for additional prospective studies, which might include an analysis of peri-OLT kidney biopsies as part of the study protocol, to dileneate the impact of pre-OLT renal dysfunction following OLT. Our study suggests that not only the etiology but also the course of of pre-OLT renal dysfunction may play a critical role.

\section{Additional material}

Additional file 1: Supplemental tables. Word DOC containing Table S1, S2, S3 and S4

\section{Acknowledgements}

The LTD was constructed by the LTD investigators and supported by the NIDDK. This manuscript was not prepared in collaboration with the LTD investigators and does not reflect the opinions of the LTD study or the NIDDK.

\section{Author details}

'Department of Medicine subsection of Nephrology, UMDNJ School of Osteopathic Medicine, Stratford, NJ, 08084, USA. ${ }^{2}$ Department of Medicine subsection Nephrology, Jersey Shore University Medical Center and Robert Wood Johnson School of Medicine New Brunswick, NJ, USA. ${ }^{3}$ Nephrology Wake Forest University Baptist Medical Center Department of Medicine, Winston-Salem, NC, 27106, USA. "University of Illinois at Chicago, Chicago, IL, 60612, USA. ${ }^{5}$ Section of Nephrology, Dept. of Medicine, Jesse Brown Veterans Administration Hospital, Chicago, IL, 60612, USA.

\section{Authors' contributions}

$J \| l$;Principal investigator, participated in design of study, statistical analysis, review, manuscript preparation and data management. Also participated in review of literature, manuscript creation and review. JD; participated data review writing manuscript editing, preparation and statistical review. JSL; participated in study design, Senior investigator statistical analysis, review, editing and preparation of manuscript. All authors read and approved final manuscript and revisions.

\section{Competing interests}

The authors declare that they have no competing interests. RESEARCH SUPPORT: This work was supported by a GRIP (Genzyme Renal Innovations Program) Award from Genzyme, Inc.

DISCLOSURES: Jerrold S. Levine, Research funding from Genzyme, Inc.

Received: 25 May 2010 Accepted: 8 November 2010

Published: 8 November 2010

\section{References}

1. Barri YM, Sanchez EQ, Jennings LW, Melton LB, Hays S, Levy MF, Klintmalm GB: Acute kidney injury following liver transplantation: definition and outcome. Liver Transpl 2009, 15(5):475-483.

2. Bilbao I, Charco R, Balsells J, Lazaro JL, Hidalgo E, Llopart L, Murio E, Margarit $C$ : Risk factors for acute renal failure requiring dialysis after liver transplantation. Clin Transplant 1998, 12(2):123-129.

3. Lima EQ, Zanetta DM, Castro I, Massarollo PC, Mies S, Machado MM, Yu L: Risk factors for development of acute renal failure after liver transplantation. Ren Fail 2003, 25(4):553-560.

4. O'Riordan A, Wong V, McQuillan R, McCormick PA, Hegarty JE, Watson AJ: Acute renal disease, as defined by the RIFLE criteria, post-liver transplantation. Am J Transplant 2007, 7(1):168-176.

5. Cabezuelo JB, Ramirez P, Rios A, Acosta F, Torres D, Sansano T, Pons JA, Bru M, Montoya M, Bueno FS, et al: Risk factors of acute renal failure after liver transplantation. Kidney International 2006, 69(6):1073-1080. 
6. Lebron Gallardo M, Herrera Gutierrez ME, Seller Perez G, Curiel Balsera E, Fernandez Ortega JF, Quesada Garcia G: Risk factors for renal dysfunction in the postoperative course of liver transplant. Liver Transplantation 2004, 10(11):1379-1385.

7. Cholongitas E, Shusang V, Marelli L, Nair D, Thomas M, Patch D, Burns A, Sweny $P$, Burroughs AK: Review article: renal function assessment in cirrhosis - difficulties and alternative measurements. Aliment Pharmacol Ther 2007, 26(7):969-978.

8. Distant DA, Gonwa TA: The kidney in liver transplantation. J Am Soc Nephrol 1993, 4(2):129-136.

9. Wei $\mathrm{YL}$, Detre KM, Everhart JE: The NIDDK liver transplantation database. Liver Transp/ Surg 1997, 3(1):10-22.

10. Mehta RL, Kellum JA, Shah SV, Molitoris BA, Ronco C, Warnock DG, Levin A: Acute Kidney Injury Network: report of an initiative to improve outcomes in acute kidney injury. Crit Care 2007, 11(2):R31.

11. Rule AD, Larson TS, Bergstralh EJ, Slezak JM, Jacobsen SJ, Cosio FG: Using serum creatinine to estimate glomerular filtration rate: accuracy in good health and in chronic kidney disease. Ann Intern Med 2004, 141(12):929-937.

12. Contreras G, Garces G, Quartin AA, Cely C, LaGatta MA, Barreto GA, Roth D, Gomez E: An epidemiologic study of early renal replacement therapy after orthotopic liver transplantation. J Am Soc Nephrol 2002, 13(1):228-233.

13. Sanchez EQ, Gonwa TA, Levy MF, Goldstein RM, Mai ML, Hays SR, Melton LB, Saracino G, Klintmalm GB: Preoperative and perioperative predictors of the need for renal replacement therapy after orthotopic liver transplantation. Transplantation 2004, 78(7):1048-1054.

14. Campbell MS, Kotlyar DS, Brensinger CM, Lewis JD, Shetty K, Bloom RD, Markmann JF, Olthoff KM, Shaked A, Reddy KR: Renal function after orthotopic liver transplantation is predicted by duration of pretransplantation creatinine elevation. Liver Transp/2005, 11(9):1048-1055.

15. Fraley DS, Burr R, Bernardini J, Angus D, Kramer DJ, Johnson JP: Impact of acute renal failure on mortality in end-stage liver disease with or without transplantation. Kidney Int 1998, 54(2):518-524.

16. Gonwa TA, McBride MA, Anderson K, Mai ML, Wadei H, Ahsan N: Continued influence of preoperative renal function on outcome of orthotopic liver transplant (OLTX) in the US: where will MELD lead us? Am J Transplant 2006, 6(11):2651-2659.

17. Velidedeoglu E, Bloom RD, Crawford MD, Desai NM, Campos L, Abt PL, Markmann JW, Mange KC, Olthoff KM, Shaked A, et al: Early kidney dysfunction post liver transplantation predicts late chronic kidney disease. Transplantation 2004, 77(4):553-556.

18. Guitard J, Cointault O, Kamar N, Muscari F, Lavayssiere L, Suc B, Ribes D, Esposito L, Barange K, Durand D, et al: Acute renal failure following liver transplantation with induction therapy. Clinical Nephrology 2006, 65(2):103-112.

19. Moreau R, Lebrec $D$ : Acute renal failure in patients with cirrhosis: perspectives in the age of MELD. Hepatology 2003, 37(2):233-243.

20. Dube GK, Cohen DJ: Simultaneous liver and kidney transplantation. Curr Opin Nephrol Hypertens 2007, 16(6):547-553.

21. Davis $\mathrm{CL}$, Gonwa TA, Wilkinson AH: Identification of patients best suited for combined liver-kidney transplantation: part II. Liver Transp/ 2002, 8(3):193-211.

22. Aberg F, Koivusalo AM, Hockerstedt K, Isoniemi H: Renal dysfunction in liver transplant patients: comparing patients transplanted for liver tumor or acute or chronic disease. Transpl Int 2007, 20(7):591-599.

23. Marik PE, Wood K, Starzl TE: The course of type 1 hepato-renal syndrome post liver transplantation. Nephrol Dial Transplant 2006, 21(2):478-482.

24. Peralta C, Prats N, Xaus C, Gelpi E, Rosello-Catafau J: Protective effect of liver ischemic preconditioning on liver and lung injury induced by hepatic ischemia-reperfusion in the rat. Hepatology 1999, 30(6):1481-1489.

25. Yamasowa $H$, Shimizu S, Inoue $T$, Takaoka $M$, Matsumura $Y$ : Endothelial nitric oxide contributes to the renal protective effects of ischemic preconditioning. J Pharmacol Exp Ther 2005, 312(1):153-159.

26. Herrmann $\mathrm{J}$ : Remote Ischemic Preconditioning Reduces Myocardial Ischemia/Reperfusion Injury. J Surg Res 2009, 159(2):660-662.

27. Xue JL, Daniels F, Star RA, Kimmel PL, Eggers PW, Molitoris BA, Himmelfarb J, Collins AJ: Incidence and mortality of acute renal failure in Medicare beneficiaries, 1992 to 2001. J Am Soc Nephrol 2006, 17(4):1135-1142
28. Thakar CV, Liangos O, Yared JP, Nelson D, Piedmonte MR, Hariachar S, Paganini EP: ARF after open-heart surgery: Influence of gender and race. Am J Kidney Dis 2003, 41(4):742-751.

29. Porayko MK, Textor SC, Krom RA, Hay JE, Gores GJ, Richards TM, Crotty PH, Beaver SJ, Steers JL, Wiesner RH: Nephrotoxic effects of primary immunosuppression with FK-506 and cyclosporine regimens after liver transplantation. Mayo Clin Proc 1994, 69(2):105-111.

30. Platz KP, Mueller AR, Blumhardt G, Bachmann S, Bechstein WO, Kahl A, Neuhaus P: Nephrotoxicity following orthotopic liver transplantation. A comparison between cyclosporine and FK506. Transplantation 1994, 58(2):170-178.

31. McCauley J, Takaya S, Fung J, Tzakis A, Abu-Elmagd K, Jain A, Todo S, Starzl TE: The question of FK 506 nephrotoxicity after liver transplantation. Transplant Proc 1991, 23(1 Pt 2):1444-1447.

32. Jindal RM, Popescu I: Renal dysfunction associated with liver transplantation. Postgrad Med J 1995, 71(839):513-524.

33. Lee JB, Winstead PS, Cook AM: Pharmacokinetic alterations in obesity. Orthopedics 2006, 29(11):984-988.

34. Cave MC, Hurt RT, Frazier TH, Matheson PJ, Garrison RN, McClain CJ, McClave SA: Obesity, inflammation, and the potential application of pharmaconutrition. Nutr Clin Pract 2008, 23(1):16-34.

35. Yamamoto S, Sato Y, Ichida T, Kurosaki I, Nakatsuka H, Hatakeyama K: Acute renal failure during the early postoperative period in adult living-related donor liver transplantation. Hepatogastroenterology 2004, 51(60):1815-1819.

36. Mascarenhas R, Gurakar A: Recent advances in liver transplantation for the practicing gastroenterologist. Gastroenterol Hepatol (N Y) 2009, 5(6):443-450.

37. Hoffmann K, Weigand MA, Hillebrand N, Buchler MW, Schmidt J, Schemmer $P$ : Is veno-venous bypass still needed during liver transplantation? A review of the literature. Clin Transplant 2009, 23(1):1-8.

38. Mehrabi A, Fonouni H, Muller SA, Schmidt J: Current concepts in transplant surgery: liver transplantation today. Langenbecks Arch Surg 2008, 393(3):245-260.

39. Abbasoglu O: Liver transplantation: yesterday, today and tomorrow. World J Gastroenterol 2008, 14(20):3117-3122.

40. Davis CL, Feng S, Sung R, Wong F, Goodrich NP, Melton LB, Reddy KR, Guidinger MK, Wilkinson A, Lake J: Simultaneous liver-kidney transplantation: evaluation to decision making. Am J Transplant 2007, 7(7):1702-1709.

41. Detry O, De Roover A, Coimbra C, Detroz B, Delwaide J, Kaba A, Polus M, Lamproye A, Joris J, Belaiche J, et al: [Recent advances in liver surgery and transplantation]. Rev Med Liege 2007, 62(5-6):310-316.

\section{Pre-publication history}

The pre-publication history for this paper can be accessed here: http://www.biomedcentral.com/1471-2369/11/30/prepub

doi:10.1186/1471-2369-11-30

Cite this article as: Iglesias et al:: Risk factors for acute kidney injury following orthotopic liver transplantation: the impact of changes in renal function while patients await transplantation. BMC Nephrology 2010 11:30.

\section{Submit your next manuscript to BioMed Central and take full advantage of:}

- Convenient online submission

- Thorough peer review

- No space constraints or color figure charges

- Immediate publication on acceptance

- Inclusion in PubMed, CAS, Scopus and Google Scholar

- Research which is freely available for redistribution 